\title{
Short-term safety of facial rejuvenation using an absorbable polydioxanone monofilament thread in patients with mild-to-moderate facial skin sagging
}

\author{
Moon Seop Choi ${ }^{1}$, \\ Hyeon Seob Byeon', \\ Hyoung Jin Moon ${ }^{3}$ \\ ${ }^{1}$ Grace Plastic Surgery Clinic, Seoul; \\ ${ }^{2}$ Songdo IB Clinic, Incheon; ${ }^{3} \mathrm{BeUp}$ \\ Aesthetic Plastic Surgery Clinic, Seoul, \\ Korea
}

\begin{abstract}
Background Facial rejuvenation techniques using thread lifts are performed by passing sutures under the facial skin to treat sagging and facial flaccidity, and their advantages include a relatively short recovery time and relatively small incisions. In this study, we describe the short-term safety of a facial rejuvenation technique involving an absorbable polydioxanone monofilament thread (Mint Lift) in patients with mild-to-moderate facial skin sagging.

Methods The current multicenter, retrospective, case-series study was conducted in a total of 196 patients who visited the Grace Plastic Surgery Clinic or the Songdo IB Clinic between 2016 and 2018. The patients underwent insertion of the Mint Lift 43 and 17 in the deep temporal fascia and the deep subcutaneous layer, respectively. Of these patients, 179 met the eligibility criteria and their medical records were retrospectively reviewed.

Results The patients comprised six men (3.4\%) and 173 women (96.6\%), with a mean age of $44.4 \pm 14.4$ years. In our series, postoperative complications included ecchymosis (1.7\%), infection (0.4\%), thread extrusion (1.1\%), and skin dimpling (1.5\%). No cases of iatrogenic nerve injury were observed, and all postoperative complications spontaneously resolved.

Conclusions The Mint Lift 43 and 17 may be safe for thread lifting in patients with mildto-moderate facial skin sagging. However, further long-term follow-up studies are warranted.
\end{abstract}

Keywords Face / Skin / Rejuvenation / Rhytidoplasty

\section{INTRODUCTION}

Over the past decade, facial rejuvenation procedures using surgical lifting through excision of redundant skin have been considered the gold standard $[1,2]$. However, surgical facial rejuvenation pro-

Received: Sep 27, 2019 Revised: Dec 17, 2019 Accepted: Jan 13, 2020 Correspondence: Moon Seop Choi Grace Plastic Surgery Clinic, 5F, 623, Gangnam-daero, Seocho-gu, Seoul 06524, Korea

Tel: +82-2-555-8558, Fax: +82-2-556-7582, E-mail: mschoi@graceclinic.co.kr

Copyright @ 2020 The Korean Society for Aesthetic Plastic Surgery.

This is an Open Access article distributed under the terms of the Creative Commons Attribution Non-Commercial License (https://creativecommons.org/licenses/by-nc/4.0/) which permits unrestricted non-commercial use, distribution, and reproduction in any medium, provided the original work is properly cited. $\quad w w w . e-a a p s . o r g$ cedures may still produce postoperative complications such as infection, skin necrosis, hematoma, seroma, and damage to the branches of the facial nerve. Disadvantages also include visible scars and a prolonged recovery time $[3,4]$. Patients are therefore in need of minimally invasive facial rejuvenation techniques with lower morbidity and relatively rapid wound healing [3]. This has led to the introduction of novel nonsurgical facial rejuvenation procedures with volumizing effects. However, the disadvantages of these procedures include increased facial volume, unnatural contour, and a visible shift of the center of gravity to the lower third of the face [2,4-6]. Ablative or non-ablative resurfacing techniques are effective in improving the skin surface, but their disadvantages include a lack of sufficient lifting of the underlying ptotic tissues $[7,8]$. 
Facial rejuvenation techniques involving thread lifts are performed by passing sutures under the facial skin to treat sagging and facial flaccidity, and their advantages include a relatively short recovery time and relatively small incisions $[6,9]$. As such, facial rejuvenation techniques using threads are considered an alternative to conventional rhytidectomy procedures $[10,11]$. Their efficacy, safety, and durability therefore deserve special attention from four standpoints: (1) treatment effects, (2) sustainability, (3) in vivo safety, and (4) the risk of serious adverse events, such as intraoperative damage to the facial nerve [6].

Mint Lift (HansBiomed Co., Ltd., Seoul, Korea) is a violet-colored, absorbable polydioxanone monofilament thread with a wire length of $43 \mathrm{~cm}$ and a United States Pharmacopeia size of 0. Classified as a class IV medical device, its properties include transparency visible during the first postoperative month, bidirectional helical barbs that providing strong initial skin anchorage, and a lack of attachment of the yarn to the needle. It is initially inserted using a curved needle (5/8) and then later using an 18-gauge blunt cannula, for which a disposable external trocar is concomitantly used $[9,12]$.

Given this background, we describe the short-term safety of a facial rejuvenation technique using the Mint Lift in patients with mild-to-moderate facial skin sagging.

\section{METHODS}

\section{Study patients and setting}

The current multicenter, retrospective, case-series study was conducted in a total of 196 patients who visited two local clinics in Seoul, Korea between 2016 and 2018. The inclusion criteria for the current study were as follows: (1) apparent good health; (2) mildto-moderate skin sagging; (3) facial rejuvenation surgery performed using the Mint Lift 17 or 43; and (4) available follow-up data. The exclusion criteria for the current study were as follows: (1) a past history of incisional facelift within the 12 months prior to undergoing facial rejuvenation at a study center; (2) loss to follow-up $(\mathrm{n}=17)$; and (3) otherwise ineligible for the current analysis according to our judgment $(n=0)$.

As such, we evaluated a total of 179 patients in the current study; informed consent was waived due to the study's retrospective nature. The current study was conducted in compliance with the relevant ethical guidelines.

\section{Surgical design and technique}

The surgical procedure was performed under local anesthesia using $1 \%$ to $2 \%$ lidocaine hydrochloride mixed with epinephrine hemitartrate at a ratio of 1:200,000 at the needle insertion point and the exit point along the passage line for thread insertion.

For the surgical design and technique using the Mint Lift 43 and 17 threads, both the entry and exit points were designed on one side of the face.

The entry points for the Mint Lift 43 were located in the temporal region; two entry points were chosen $2 \mathrm{~cm}$ medial to the temporal hair line, superior to the superior helix of the ear, with a gap distance of approximately $2-3 \mathrm{~cm}$. After a slit incision was made, the Mint Lift 43 was anchored to the entry and exit points using a specialized needle. This was followed by insertion of a two-piece cannula into the entry and exit points and removal of the inner guide. Then, two or three Mint Lift 43 threads were inserted into the outer cannula in the deep temporal fascia using a specialized needle, such as a temporal needle, and were then pulled through the exit point. The outer cannula was then removed. During this process, special attention should be paid to the passage of the outer cannula through the deep subcutaneous layer.

For the insertion of the Mint Lift 17, two or three entry points were chosen along the hair line, and the exit point was at the target site $1 \mathrm{~cm}$ proximal to the nasolabial folds or the apex of the jowl. Unlike in the insertion of the Mint Lift 43, no passage of the Mint Lift 17 through the exit point was required. For the insertion of the Mint Lift 17, a small hole was made at the entry point using an 18-gauge needle, and a two-piece cannula was inserted. Upon advancement through the deep subcutaneous layer to the target site, the inner guide was removed and three or four Mint Lift 17 threads were inserted. This was followed by the removal of the outer cannula.

\section{Patient evaluation and criteria}

All data from our clinical series of patients were expressed as mean \pm standard deviation or as the number of cases and corresponding percentage, where appropriate. Moreover, the safety profile of this technique was assessed in terms of the incidence of postoperative complications.

Table 1. Baseline characteristics of the patients

\begin{tabular}{lccc}
\hline Variable & Total & $\begin{array}{c}\text { Grace Plastic } \\
\text { Surgery Clinic } \\
\text { (n=107) }\end{array}$ & $\begin{array}{c}\text { Songdo } \\
\text { IB Clinic } \\
\text { (n=72) }\end{array}$ \\
\hline $\begin{array}{l}\text { Age lyr) } \\
\text { Sex }\end{array}$ & $44.4 \pm 14.4$ & $40.7 \pm 12.1$ & $49.9 \pm 15.7$ \\
Male & $6(3.4)$ & $4(3.7)$ & $2(2.8)$ \\
Female & $173(96.6)$ & $103(96.3)$ & $70(97.2)$ \\
Nationality & $131(73.2)$ & $75(70.1)$ & $56(77.8)$ \\
Korean & $26(14.6)$ & $24(22.4)$ & $2(2.8)$ \\
Chinese & $22(12.2)$ & $8(7.5)$ & $14(19.4)$ \\
Japanese & $22.3 \pm 9.8$ & $22.5 \pm 9.6$ & $21.9 \pm 10.1$ \\
Follow-up period (mo) & & & \\
\hline
\end{tabular}

Values are presented as mean \pm SD or number $(\%)$. 

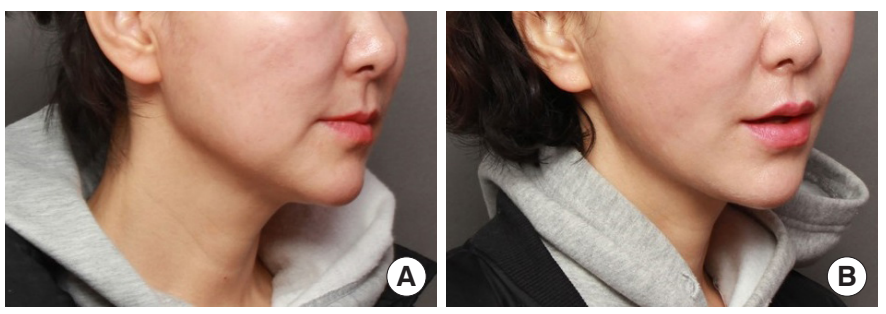

Fig. 1. A 44-year-old woman receiving the Mint Lift 43 at 3 months. (A) A 44-year-old woman visited us with a chief concern of skin sagging on the right side of the face, for which she underwent facial rejuvenation using the Mint Lift 43. Two threads were inserted in the deep temporal fascia, a process in which special attention should be paid to the passage of the outer cannula through the deep subcutaneous layer. (B) At 3 months, the patient was satisfied with the treatment outcomes and reported no postoperative complications.

\section{RESULTS}

\section{Baseline characteristics of patients}

Our clinical series included 179 patients (six men and 173 women; mean age, $44.4 \pm 14.4$ years). The mean follow-up was $22.3 \pm 9.8$ months. In total, 107 and 72 patients were treated at the Grace Plastic Surgery Clinic and the IB Plastic Surgery Clinic, respectively. The baseline characteristics of the patients are presented in Table 1.

\section{Illustrative cases}

Treatment outcomes were described using photographs taken preoperatively and at 3 or 6 months, for which two representative cases are illustrated (Figs. 1,2).

\section{Safety outcomes}

In our series, the postoperative complications included ecchymosis $(1.7 \%)$, infection $(0.4 \%)$, thread extrusion (1.1\%), and skin dimpling (1.5\%). No cases of iatrogenic nerve injury were observed, and all postoperative complications spontaneously resolved.

\section{DISCUSSION}

Over the past several years, there have been marked changes in facial rejuvenation techniques using absorbable thread lifts with polydioxanone threads [13-16].

Thread lifts are used for nonsurgical facial tightening. Ideal requirements for threads used in these procedures include biological inertness, lack of tissue reaction, ease of handling, ease of knotting, lack of bacterial growth, high tensile strength, ease of sterilization, lack of an allergic reaction, lack of carcinogenicity, and high absorbability [15-17]. High biodegradability in body fluids and high tensile strength are particularly essential features of thread lifts, because the material used for thread lifts should be strong, but also should easily dissolve at the same rate as that at which the tissue
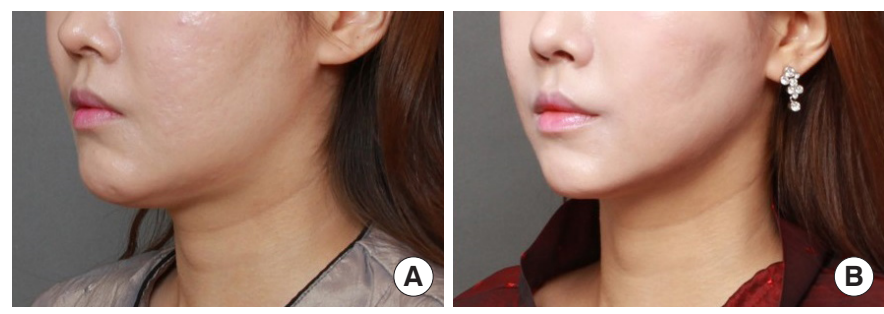

Fig. 2. A 31-year-old woman receiving the Mint Lift 17 at 6 months. (A) A 31-year-old woman with skin sagging on the left side of the face underwent insertion of four Mint Lift 17 threads in the deep subcutaneous layer. (B) At 6 months, the patient was satisfied with the treatment outcomes and reported no postoperative complications.

gains strength [18].

It is apparent that no single thread lift fulfills all of the above criteria. Plastic surgeons should therefore select the optimal thread lift based on the type of aesthetic procedure they plan to perform. This issue is also closely associated with a lack of consistent requirements for thread lifts when these tools are used to lift the skin $[10,19]$. Finally, the use of optimal thread lifts for aesthetic facial treatments is an essential factor for both obtaining good cosmetic results and avoiding complications [6,14,15,20-22].

In our series, only nonserious complications were encountered, such as ecchymosis, infection, thread extrusion, and skin dimpling, all of which spontaneously resolved. These results indicate that Mint Lift is a safer modality than other facial lifting procedures or surgical methods; this may be due to the simplicity of the procedure, the low risk of iatrogenic tissue injuries, and differential features of our techniques, such as the use of a specialized cannula and absorbable sutures, as well as variability in the depth of cannula insertion. The short-term safety of the Mint Lift has been documented previously. According to Baek et al. [12], only a few minor complications arose with no notable problems in a 24-week, prospective, single-center, single-arm, pre-post test design, open-label clinical study of 61 patients with deep nasolabial folds and lower facial drooping (three men and 58 women). Those complications included pustule formation, pain, swelling, a subjective feeling of tightness, and skin dimpling, although they were mostly self-limited. Thus, Baek et al. concluded that facial rejuvenation using the Mint Lift may be a favorable modality. Moreover, in a separate study, Bae et al. [23] reported no major complications such as thread exposure, alopecia, or parotid gland injury. Although five patients complained of ecchymosis for up to 3 weeks, they did not require treatment and returned to their daily lives within 1 week postoperatively.

Herein, we describe the safety of a facial rejuvenation technique using the Mint Lift with a review of previous published studies on this topic. However, further long-term follow-up studies are warranted to corroborate our results. 


\section{NOTES}

\section{Conflict of interest}

This study was supported by HansBiomed Co., Ltd. No other potential conflict of interest relevant to this article was reported.

\section{Ethical approval}

The study was performed in accordance with the principles of the Declaration of Helsinki.

\section{Patient consent}

The patients provided written informed consent for the publication and the use of their images.

\section{ORCID}

Moon Seop Choi

Hyeon Seob Byeon

Hyoung Jin Moon

https://orcid.org/0000-0002-2307-5115

https://orcid.org/0000-0002-6574-054X

https://orcid.org/0000-0001-5236-6328

\section{REFERENCES}

1. Barrett DM, Casanueva FJ, Wang TD. Evolution of the rhytidectomy. World J Otorhinolaryngol Head Neck Surg 2016;2:38-44.

2. Chuang J, Barnes C, Wong BJF. Overview of facial plastic surgery and current developments. Surg J (N Y) 2016;2:e17-28.

3. Kaminer MS, Bogart M, Choi C, et al. Long-term efficacy of anchored barbed sutures in the face and neck. Dermatol Surg 2008;34:1041-7.

4. Wu WT. Barbed sutures in facial rejuvenation. Aesthet Surg J 2004;24: 582-7.

5. Paul MD. Barbed sutures for aesthetic facial plastic surgery: indications and techniques. Clin Plast Surg 2008;35:451-61.

6. Villa MT, White LE, Alam M, et al. Barbed sutures: a review of the literature. Plast Reconstr Surg 2008;121:102e-108e.

7. Atiyeh BS, Dibo SA. Nonsurgical nonablative treatment of aging skin: radiofrequency technologies between aggressive marketing and evidence-based efficacy. Aesthetic Plast Surg 2009;33:283-94.

8. Preissig J, Hamilton K, Markus R. Current laser resurfacing technologies: a review that delves beneath the surface. Semin Plast Surg 2012; 26:109-16.
9. Yarak S, de Carvalho JAR. Facial rejuvenation with absorbable and barbed thread lift: case series with Mint Lift ${ }^{\mathrm{TM}}$. J Clin Exp Dermatol Res 2017;8:415.

10. Garvey PB, Ricciardelli EJ, Gampper T. Outcomes in threadlift for facial rejuvenation. Ann Plast Surg 2009;62:482-5.

11. Han HH, Kim JM, Kim NH, et al. Combined, minimally invasive, thread-based facelift. Arch Aesthetic Plast Surg 2014;20:160-4.

12. Baek WI, Kim WS, Suh JH, et al. Lower facial rejuvenation using absorbable casting barbed thread. Dermatol Surg 2017;43:884-7.

13. Yeo SH, Lee YB, Han DG. Early complications from absorbable anchoring suture following thread-lift for facial rejuvenation. Arch Aesthetic Plast Surg 2017;23:11-6.

14. Abraham RF, DeFatta RJ, Williams EF 3rd. Thread-lift for facial rejuvenation: assessment of long-term results. Arch Facial Plast Surg 2009; 11:178-83.

15. Savoia A, Accardo C, Vannini F, et al. Outcomes in thread lift for facial rejuvenation: a study performed with happy lift ${ }^{\mathrm{ma}}$ revitalizing Dermatol Ther (Heidelb) 2014;4:103-14.

16. Dennis C, Sethu S, Nayak S, et al. Suture materials: current and emerging trends. J Biomed Mater Res A 2016;104:1544-59.

17. Suh DH, Jang HW, Lee SJ, et al. Outcomes of polydioxanone knotless thread lifting for facial rejuvenation. Dermatol Surg 2015;41:720-5.

18. Svensson RB, Hassenkam T, Grant CA, et al. Tensile properties of human collagen fibrils and fascicles are insensitive to environmental salts. Biophys J 2010;99:4020-7.

19. Kang SH, Byun EJ, Kim HS. Vertical lifting: a new optimal thread lifting technique for Asians. Dermatol Surg 2017;43:1263-70.

20. Sulamanidze M, Sulamanidze G, Vozdvizhensky I, et al. Avoiding complications with Aptos sutures. Aesthet Surg J 2011;31:863-73.

21. Bertossi D, Botti G, Gualdi A, et al. Effectiveness, longevity, and complications of facelift by barbed suture insertion. Aesthet Surg J 2019;39: 241-7.

22. Sulamanidze MA, Paikidze TG, Sulamanidze GM, et al. Facial lifting with "APTOS" threads: featherlift. Otolaryngol Clin North Am 2005; 38:1109-17.

23. Bae KI, Han DG, Kim SE, et al. Minimally invasive facial rejuvenation combining thread lifting with liposuction: a clinical comparison with thread lifting alone. Arch Aesthetic Plast Surg 2019;25:52-8. 